\section{Response to Santoro et al}

\section{Gareth Evans}

Published online: 5 September 2014

(c) Springer Science+Business Media New York 2014

We are grateful to Santoro et al. for commenting on our paper [1]. We agree that more work is necessary to compare outcomes in high risk women screened with breast MRI compared to no intensive screening. We also agree that obtaining such a control group is increasingly difficult. We are also in agreement that the current results in terms of tumor size, lymph node status, and survival are nonetheless encouraging. We acknowledge that we had overlooked the HIBCRIT Study final results paper [2] and thank Santoro et al. for bringing this to our attention.

Yours truly,

Prof D Gareth Evans MD FRCP

This rebuttal letter refers to the letter to the editor article available at 10.1007/s10549-014-3097-1.

D. Gareth Evans $(\square)$

Genomic Medicine, The University of Manchester, MAHSC,

Oxford Rd, Manchester M13 9WL, UK

e-mail: gareth.evans@cmft.nhs.uk

\section{References}

1. Gareth ED, Nisha K, Yit L et al (2014) MRI breast screening in high-risk women: cancer detection and survival analysis. Breast Cancer Res Treat 145:663-672

2. Sardanelli F, Podo F, Santoro F et al (2011) Multicenter surveillance of women at high genetic breast cancer risk using mammography, ultrasonography, and contrast-enhanced magnetic resonance imaging (the High Breast Cancer Risk Italian 1 Study) Final results. Invest Radiol 46:94-105 